\title{
Recorrido por el patrimonio geológico y minero del Bajo Aragón, desde La Venta de la Pintada a Los Olmos, Alcorisa y Alcañíz
}

Josep Maria Mata-Perelló

Andrés Pocoví Juan

Joaquim Sanz Balagué

Jaume Vilaltella

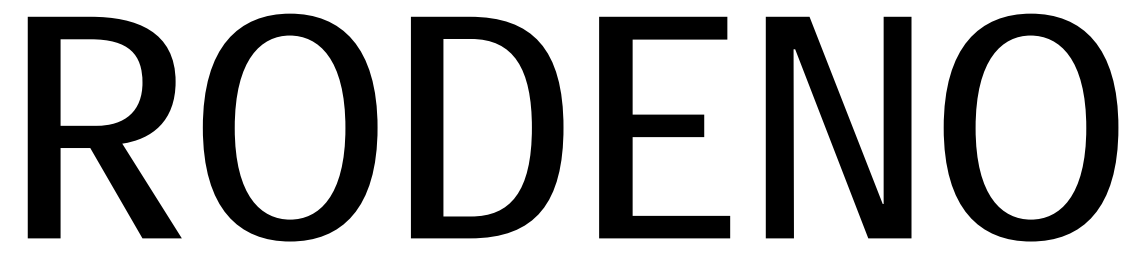

\section{REVISTA DE GEOLOGÍA ARAGONESA}

\section{n. 2}

JUNIO 2015 


\title{
RECORRIDO POR EL PATRIMONIO GEOLÓGICO Y MINERO DEL BAJO ARAGÓN, DESDE LA VENTA DE LA PINTADA A LOS OLMOS, ALCORISA Y ALCAÑÍZ
}

\author{
Josep Maria Mata-Perelló \\ Museu de geologia Valentí Masachs, Escola Politècnica Superior d'Enginyeria de Manresa \\ (EPSEM), Universitat Politècnica de Catalunya · BarcelonaTech (UPC), 08272 Manresa, Spain
}

\author{
Andrés Pocovi Juan \\ Universidad de Zaragoza, Departamento de Ciencias de la Tierra ( DCT- UZ) \\ Joaquim Sanz Balagué \\ Departament d'Enginyeria Minera i Recursos Naturals (EMRN), Escola Politècnica Superior \\ d'Enginyeria de Manresa (EPSEM), Universitat Politècnica de Catalunya · BarcelonaTech \\ (UPC), 08272 Manresa, Spain
}

\section{Jaume Vilaltella Farràs.}

Sociedad Española para la Defensa del Patrimonio Geológico y Minero (SEDPGYM)

Palabras clave: patrimonio minero; patrimonio geológico; Zaragoza

\section{Resumen}

En esta ocasión se realizará un itinerario localizado en un área totalmente situada en la comarca del Bajo Aragón, desde principio a fin, entre las localidades de la Mata de los Olmos, los Olmos, Alcorisa, Calanda y Alcañíz (la capital administrativa de esta comarca).

Por otra parte, el recorrido se centrará en un principio en el Sistema Ibérico (entre la Venta de la Pintada), para entrar después en la Depresión Geológica del Ebro, que ya no se abandonará hasta el fin del recorrido.

En el primer tramo se Irán encontrando diferentes afloramientos de los materiales mesozoicos y de los materiales cenozoicos. En el primer caso, nos encontraremos fundamentalmente con afloramientos de los materiales del Jurásico y sobretodo del Cretácico, fundamentalmente del Albiense. Precisamente, algunas de las diferentes paradas del recorrido las efectuaremos en los afloramientos de la Formación Utrillas y otros en los de la Formación Escucha. Por lo que concierne a los afloramientos de los materiales cenozoicos, cabe señalar que en su mayoría pertenecen al Oligoceno, el cual recubre parte de las formaciones mesozoicas mencionadas anteriormente. 
Mientras que en el segundo tramo (el que efectuaremos entre Alcorisa y Alcañíz) iremos encontrando afloramientos cenozoicos, fundamentalmente del Oigoceno y del Eoceno, que son los que rellenan la Depresión Geológica del Ebro.

No obstante, a lo largo del recorrido nos centraremos fundamentalmente en el conocimiento del Patrimonio Geológico y Minero. Sin duda alguna, la conservación, valorización y utilización de este patrimonio es un importante factor económico a tener en cuenta.

\section{Objetivos generales de este itinerario}

En la realización de este itinerario geológico y minero, se perseguirá la consecución de los siguientes objetivos generales, a lo largo del desarrollo del mismo:

1. Observación general de la estructura del Sistema Ibérico, a través del cual se desarrollará la primera parte del recorrido del itinerario. En concreto, este recorrido se va a realizar íntegramente por los sectores correspondientes a la Rama Aragonesa; muy cerca de su contacto con la Depresión Geológica del Ebro.

2. Observación de los materiales geológicos del Mesozoico que constituyen los afloramientos del Sistema Ibérico, por los alrededores de los municipios de la Mata de los Olmos, los Olmos y Alcorisa; a través de los cuales discurrirá parte del itinerario. Estos materiales se distribuyen fundamentalmente entre el Jurásico y el Cretácico; aunque en su mayor parte pertenecen a este último.

3. Observación de los materiales geológicos del Cenozoico que constituyen parte de los afloramientos del Sistema Ibérico, por los alrededores de los municipios de Alcorisa y de Calanda, a través de los cuales discurrirá parte del itinerario. Estos materiales se distribuyen fundamentalmente entre el Eoceno Superior y el Oligoceno; aunque en su mayor parte pertenecen a este último.

4. Observación general de la estructura de la Depresión Geológica del Ebro, a través del cual se desarrollará la segunda parte del recorrido del itinerario, entre las poblaciones de Calanda y Alcañíz

5. Observación de los materiales geológicos del Cenozoico que constituyen los afloramientos de la Depresión Geológica del Ebro, por los alrededores de los municipios de Calanda y Alcañíz, a través de los cuales discurrirá parte del itinerario. Estos materiales se distribuyen fundamentalmente entre el Eoceno Superior y el Oligoceno.

6. Observación de las diferentes explotaciones mineras; tanto de las de carácter subterráneo como de las realizadas a cielo abierto (que son las que ahora predominan) Estas explotaciones se hallan dedicadas a la extracción de los niveles caoliníferos en su mayoría y también a los lignitíferos. Se sitúan siempre entre los afloramientos de los materiales cretácicos pertenecientes según los casos a la Formación Utrillas o a la Formación Escucha.

7. Observación de los impactos producidos por las explotaciones mineras sobre el Medio Natural. Y también de la corrección de estos impactos. Aunque cabe decir que ninguna de las explotaciones que vamos a ver en este recorrido, ha tenido nunca ninguna restauración ambiental. 
8. Observación del Patrimonio Geológico, como es el caso de los distintos afloramientos de los niveles lignitíferos.

9. Observación del Patrimonio Minero generado a partir de las explotaciones anteriores; así como de otras que iremos encontrando a lo largo de este itinerario.

\section{Antecedentes bibliográficos}

No conocemos la existencia de ningún itinerario similar al que ahora presentamos. Hay, eso si, algunos recorridos nuestros que discurren por lugares cercanos. Entre ellos citaremos dos trabajos anteriores nuestros: MATA-PERELLÓ, J.M. (1995, 1996a, 1996b 1999, 2003a у 2003b).

Por otra parte, en relación con las mineralizaciones situadas en la comarca por la que discurre este itinerario, haremos mención de otro trabajo nuestro: MATA-PERELLÓ (1992), referidos al inventario mineralógico de esta comarca.

$\mathrm{Y}$, finalmente, por lo que concierne a la estructura geológica de la zona por la que va a discurrir el itinerario, haremos mención de los trabajos de: GUIMERÀ et altri (1982) y de RIBA et altri (1976), los dos son de carácter generalista.

Todos ellos figuran en el apartado dedicado a la BIBLIOGRAFIA, al final del informe del recorrido del itinerario.

\section{Recorrido del itinerario}

El recorrido se desarrollará íntegramente por la comarca del Bajo Aragón. Así se iniciará en el municipio de la Mata de los Olmos, concretamente en las cercanías de la Venta de la Pintada, en donde se efectuará la primera parada.

Luego, el recorrido se dirigirá al cercano municipio de los Olmos, por donde se efectuará una nueva parada. Tras ello, el recorrido se encaminará hacía Alcorisa, en donde se hará otra parada.

Tras ello, el recorrido se dirigirá hacía la población de Calanda. Ahí efectuaremos una nueva parada. Finalmente, el recorrido se dirigirá hacía Alcañíz, la capital comarcal. En torno a esta población efectuaremos diversas paradas, finalizando ahí el recorrido de este itinerario. 


\section{Advertencias previas}

Como en otros recorridos de RECERCA GEOLÒGICA I MINERALÒGICA... si se dispone del tiempo suficiente, podrán efectuarse todas las paradas e hijuelas indicadas en el guión. En caso contrario, recomendamos prescindir de las denominadas PARADAS - CONDICIONALES.

También es necesario, en todo momento, tener en cuenta que una parte del recorrido se efectuará por caminos de tierra, circunstancia por la cual convendrá tomar las debidas precauciones. Así se hará el recorrido de acceso a alguna de las explotaciones caoliníferas de los Olmos,, entre otros recorridos.

Por último y como siempre, hay que tener a lo largo de todo el recorrido, un cuidado muy especial con la Naturaleza.

\section{Descripción del itinerario}

Como ya es habitual, el recorrido del itinerario se estructurará sobre la base de una serie de PARADAS o ESTACIONES. En cada una de ellas se procederá a la observación de diferentes cuestiones específicas, ya sean mineras, geológicas o de tratamiento industrial de los materiales geológicos extraídos. En cada caso se indicará el número de la parada en el orden general del recorrido, el nombre de la misma (que podrá coincidir con el de la mina o el topónimo más cercano).

Tras ello se indicará el nombre del municipio en donde se halla la parada, y el de la comarca. Seguidamente se indicará el número del mapa topográfico (a escala 1:50.000) en donde se halla la parada. En este itinerario, utilizaremos exclusivamente las siguientes hojas editadas por el instituto Geográfico y Catastral de España: la 469 (o de Alcañíz), la 493 (llamada de Oliete) y la 494 (o de Calanda).

Así pues, a lo largo del presente itinerario que ahora se inicia, veremos las siguientes paradas:

PARADA 1. EXPLOTACIONES DE CAOLÍN DE LA VENTA DE LA PINTADA, (término municipal de la Mata de los Olmos, comarca del Bajo Aragón). (Hoja 493).

El recorrido cabe iniciarlo en las inmediaciones de la venta de la Pintada, dentro del municipio de la Mata de los Olmos, muy cerca de la carretera nacional N - 211 / N -420. En este lugar, junto a unas antiguas explotaciones de caolín, efectuaremos la primera parada de este itinerario. (fotografía 1). 


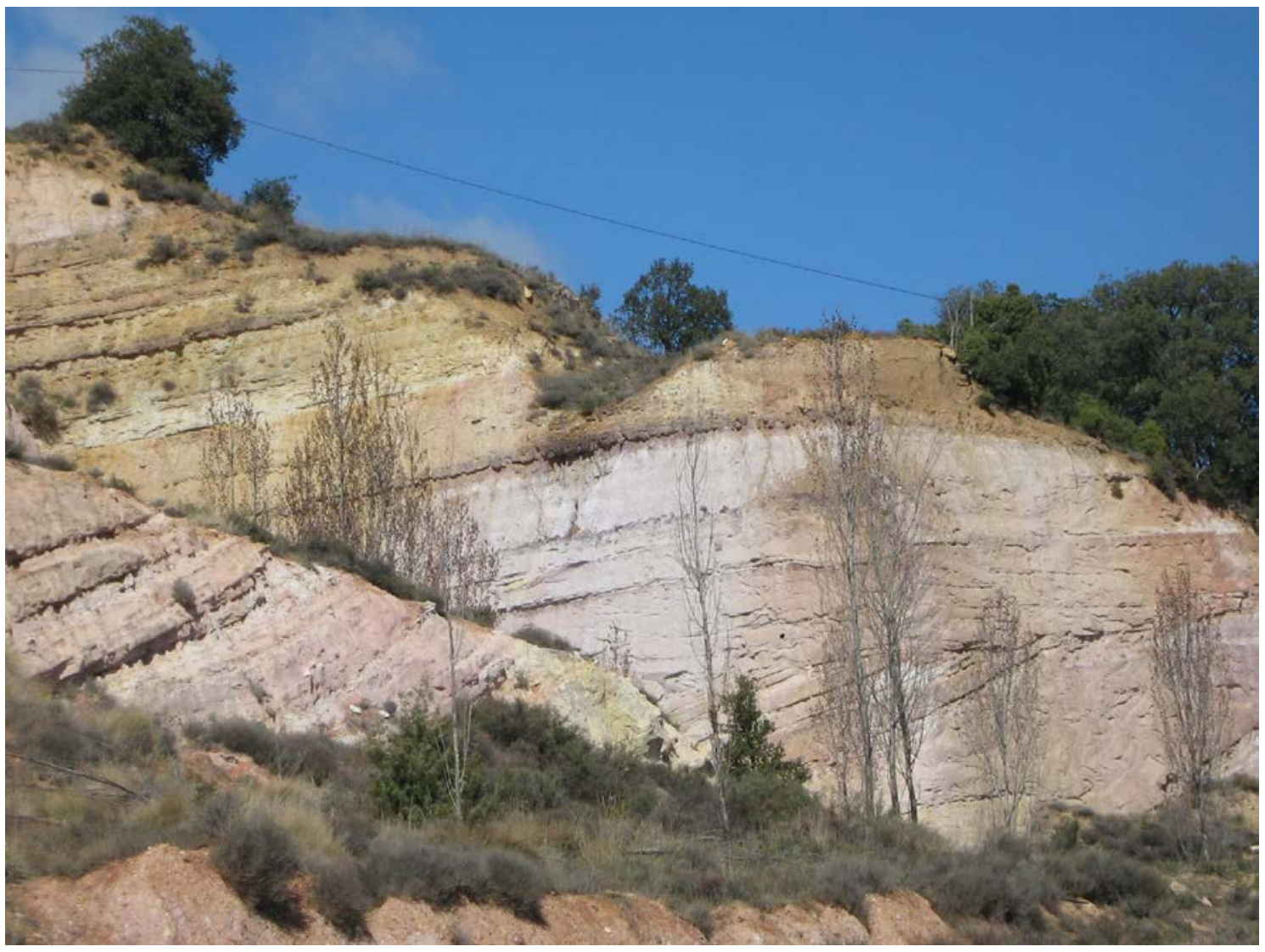

Fotografía 1. Explotaciones de caolín en la Venta de la Pintada

Este lugar se encuentra ubicado en pleno Sistema Ibérico, entre afloramientos de los materiales que constituyen la Formación Utrillas, del Albiense. Así, por los alrededores de este punto, se hacen ostensibles los niveles de caolines y arenas, con frecuentes intercalaciones de óxidos de hierro (con HEMATITES y GOETHITA) fundamentalmente, De ahí el nombre de la venta. 
PARADA 2. EXPLOTACIÓN DE CALIZAS DEL BARRANCO CENTENERA, (término municipal de los Olmos, comarca del Bajo Aragón). (Hoja 494).

Tras realizar la parada anterior, cae tomar la carretera nacional $(\mathrm{N}-211$ / N - 420) hacía el levante. De esta manera, pronto se llegara al pueblo de la Mata de los Olmos y poco después a los Olmos. Desde este pueblo, convendrá seguir algo más de $2 \mathrm{~km}$, hasta llegar a una explotación de calizas situada junto a la carretera, a la izquierda de la misma. Ahí, a unos $8 \mathrm{Km}$ de la parada anterior efectuaremos la presente.

En este recorrido, hemos ido encontrando afloramientos de los materiales citados en la parada anterior. Así, en torno al pueblo de los Olmos, hay diversas explotaciones de caolines, algunas de ellas en activo. Sin embargo, en este lugar hubo una antigua explotación de las calizas cretácicas, con la finalidad de ser utilizadas como áridos para la construcción. (fotografia 1).

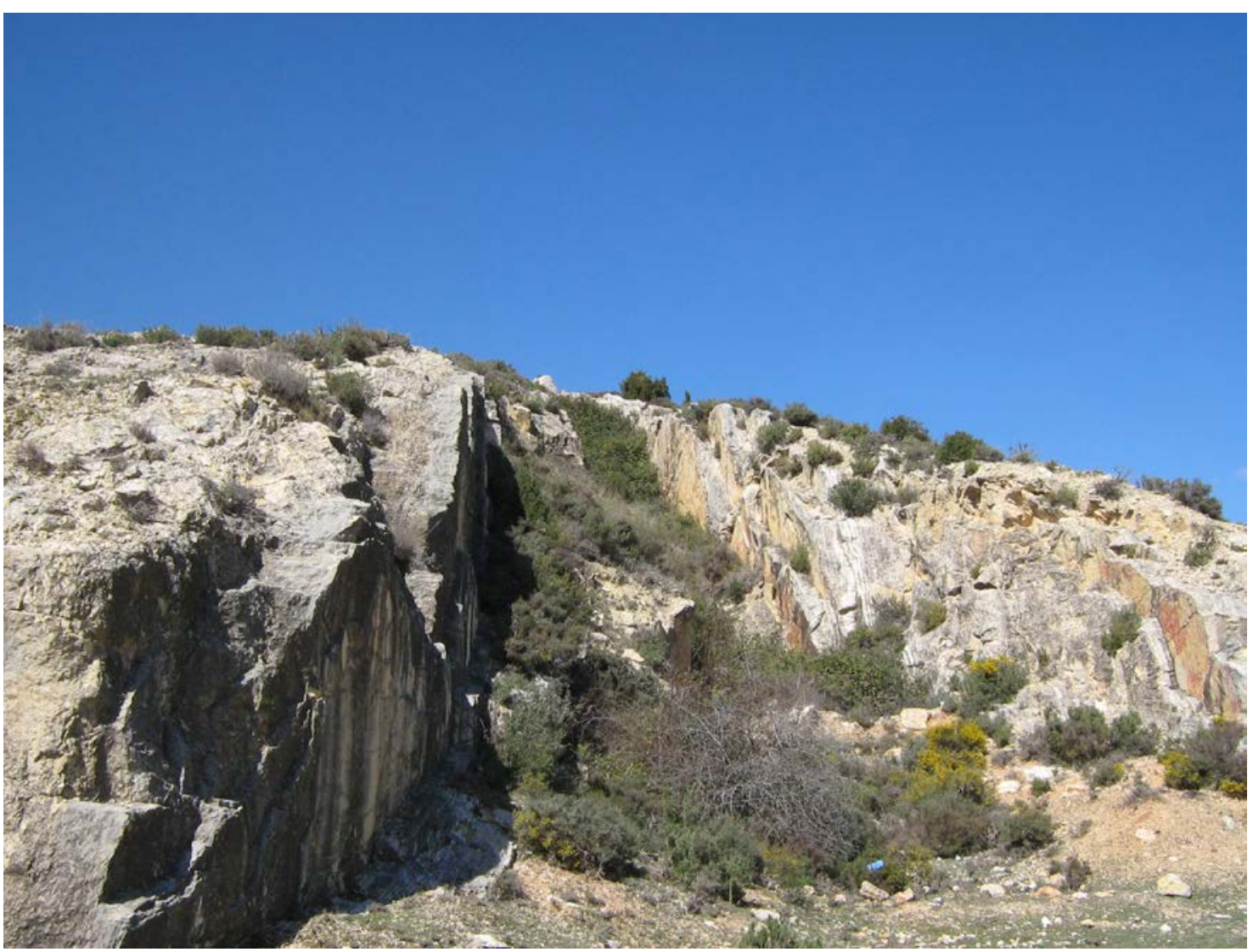

Fotografía. 2 Explotación de calizas en los Olmos 
PARADA 3. EXPLOTACIONES DE CAOLÍN DEL CERRO OLIVEROS, (término municipal de Alcorisa, comarca del Bajo Aragón). (Hoja 494).

Tras realizar la parada anterior, cabe continuar por la carretera nacional, que ahora se dirige hacia el pueblo de Alcorisa. Luego, al llegar a él y sobrepasarlo, nos convendrá seguir por la carretera que se dirige a Andorra. Por ella, al llegar al Molino Rebatillo, nos interesará remontar el río Alchoza. Éste nos llevará a las cercanías de varias explotaciones de caolín, algunas de ellas en activo. En este lugar efectuaremos una nueva parada a unos $12 \mathrm{Km}$ de la anterior.

En este recorrido, hemos ido encontrando afloramientos de los materiales mesozoicos citados en la parada anterior. Sin embargo, en las cercanías de Alcorisa habremos visto afloramientos de los materiales cenozoicos del Oligoceno.

Luego, al llegar al lugar de la parada, habremos vuelto a encontrar afloramientos de los materiales mesozoicos cretácicos de la Formación Utrillas. Precisamente, estos materiales han sido (y son) explotados en distintos lugares del Cerro Oliveros, en donde ahora estamos situados, al Norte de Alcorisa.

Cabe señalar que muchas de estas explotaciones se hallan actualmente en activo, en algunos casos intermitente. De esta forma, para acceder a ellas es necesario tener el permiso correspondiente. (fotografia 3).

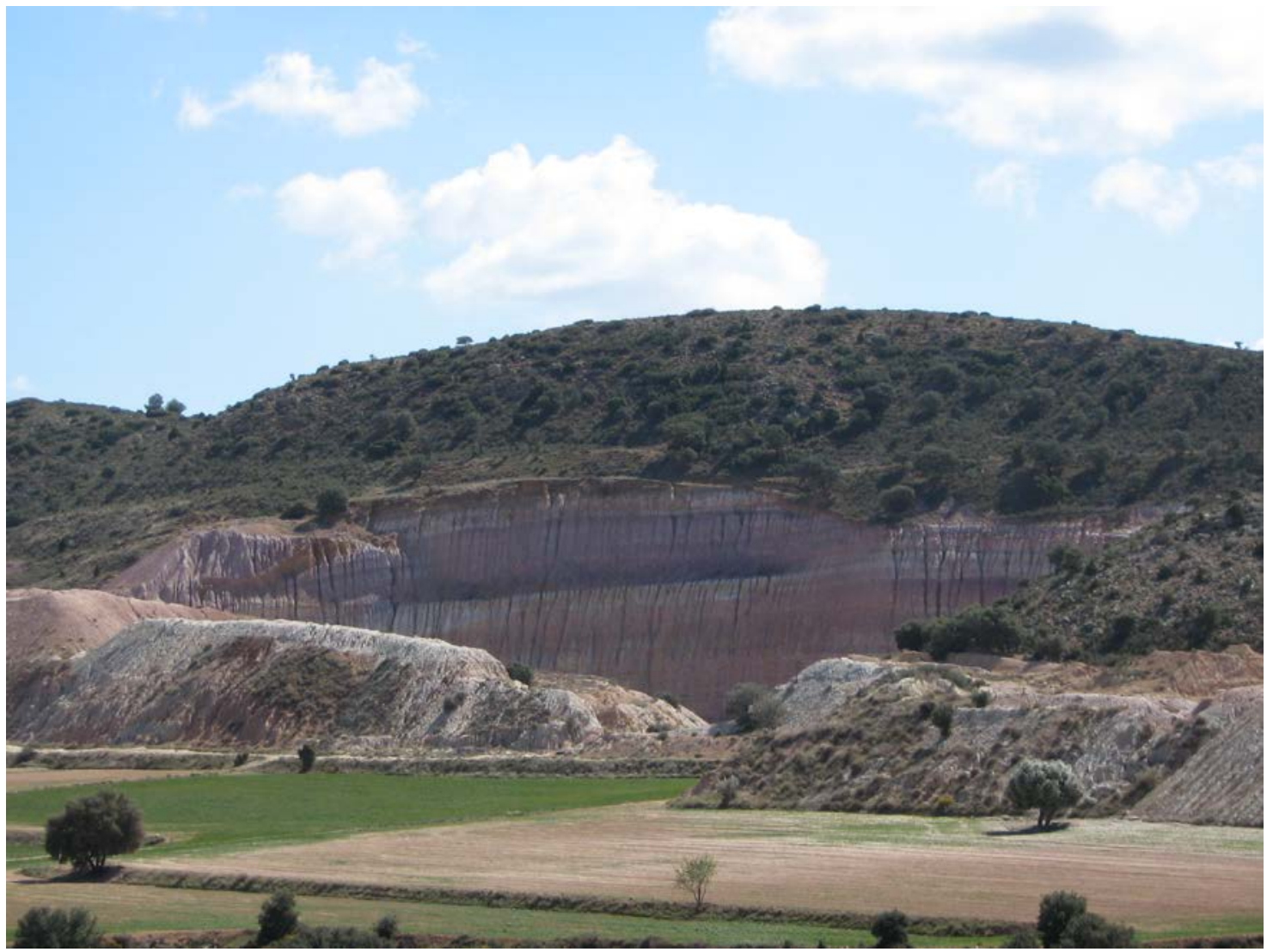

Fotografía 3. Una de las explotaciones caoliníferas del cerro Oliveras 
PARADA 4. TEJERA DE CALANDA, (término municipal de Calanda, comarca del Bajo Aragón). (Hoja 494).

Después de efectuar la parada anterior, cabe retornar a la carretera nacional de doble denominación, la N-211 / N-428. Por esta carretera pronto se llegará a Calanda, tras dejar atrás la carretera que se dirige hacía Foz Calanda. Al entrar en Calanda efectuaremos una nueva parada junto a la chimenea de la antigua Tejera de Calanda. Así, tras la parada anterior, habremos recorrido unos $15 \mathrm{Km}$ más.

En este recorrido hemos pasado (casi de forma imperceptible) del Sistema Ibérico a la Depresión Geológica del Ebro, en donde estamos ahora situados, al igual que todo el conjunto de la población de Calanda.

En este lugar había una antigua tejera, muy importante. Esta tejera, tras modernizarse ha estado activa hasta hace pocos años. En la actualidad, tras ser derruida, su solar ha quedado cubierto de casas. Sin embargo, hay una notable excepción: se trata de la chimenea. Esta se levanta por encima de las nuevas edificaciones. (fotografia 4).

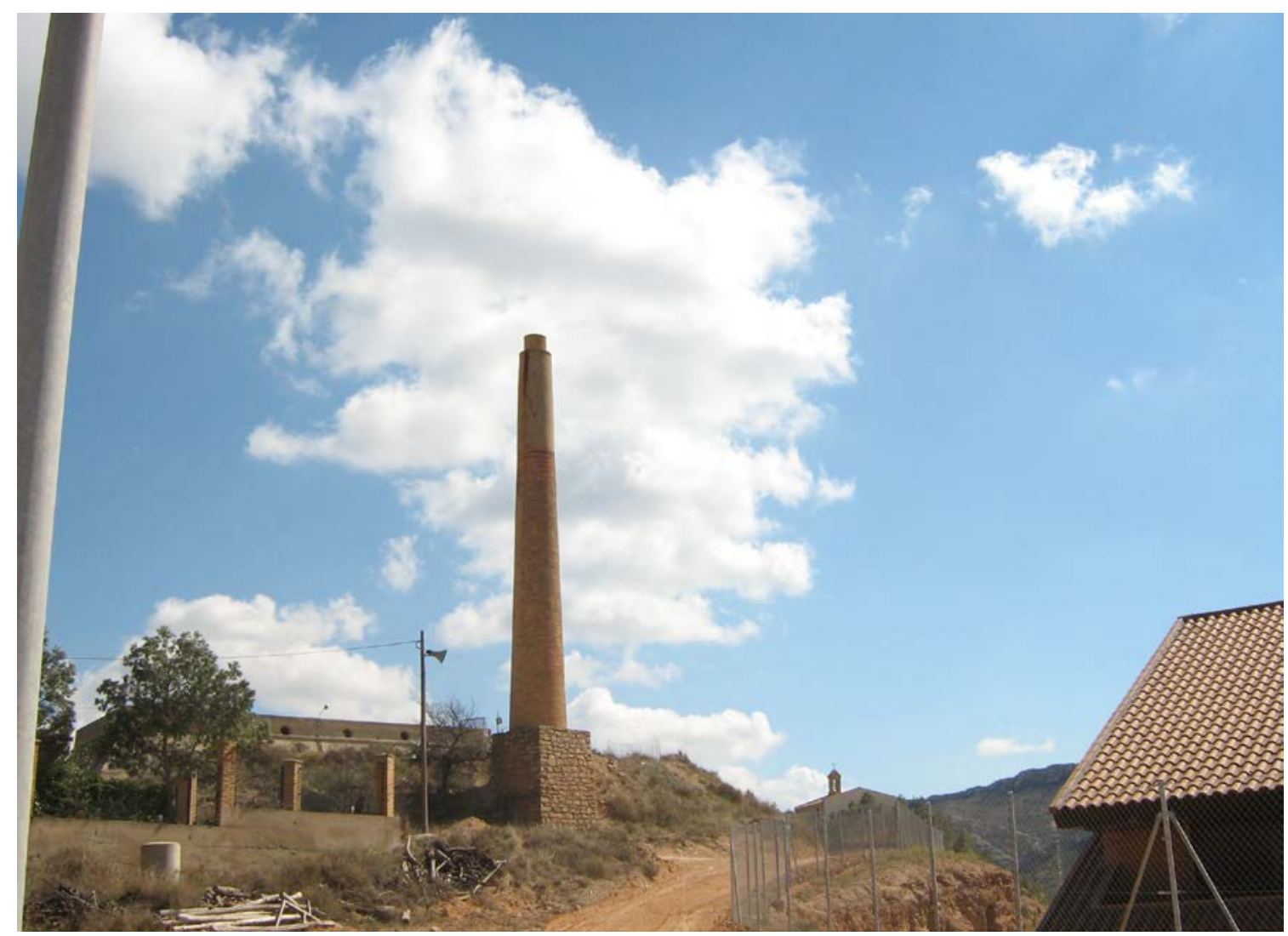

Fotografía 4. La chimenea de la antigua tejera 
PARADA 5. BALSA DE LA SALADA, (término municipal de Calanda, comarca del Bajo Aragón). (Hoja 494).

Tras la parada anterior, conviene seguir hacía Alcañíz por la carretera de doble denominación $(\mathrm{N}-211$ / N - 420). Al llegar a las inmediaciones del canal, convendrá tomar un camino que sale por la derecha de la carretera. Por él llegaremos cerca de donde está la Balsa Salada de Calanda. Ahí efectuaremos una nueva parada, aproximadamente a unos $6 \mathrm{Km}$ de la anterior.

En este recorrido habremos ido encontrando afloramientos de los materiales cenozoicos que se hallan por los alrededores de Calanda. Estos materiales forman parte de la Depresión Geológica del Ebro, en donde estamos ahora situados.

En este lugar hay una laguna endorreica. En ella se dan fenómenos de precipitación de sales (especialmente de HALITA), al tratarse de aguas salobres. Cabe tener en cuenta que antaño estas sales eran utilizadas para el consumo humano y animal.

Por otra parte, esta es una de las lagunas endorreicas que forma parte del complejo lacustre de Alcañíz - Calanda, un complejo muy importante dentro del patrimonio geológico del bajo Aragón. (fotografia 5).

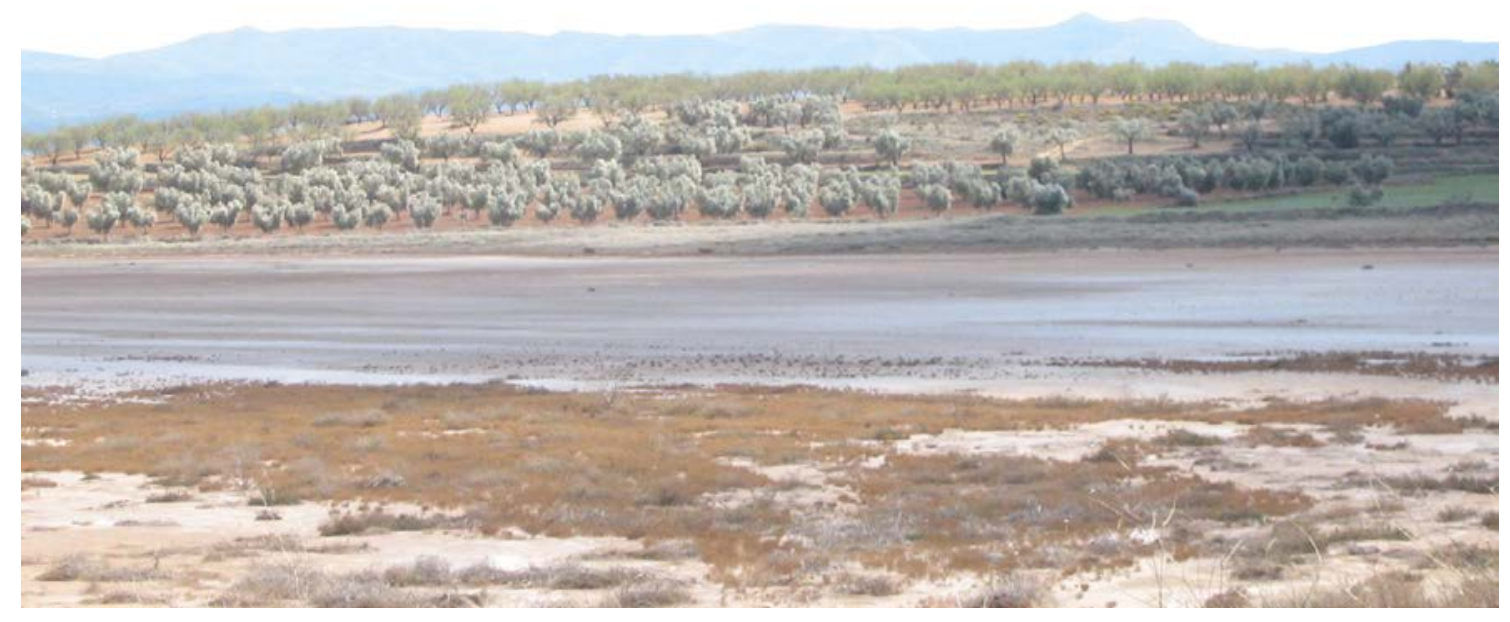

Fotografía 5. La Balsa Salada de Calanda 
PARADA 6. LA SALADA GRANDE, (término municipal de Alcañíz comarca del Bajo Aragón). (Hoja 469).

Tras realizar la parada anterior, cabe retornar hacía la carretera nacional. Ahí será conveniente seguir hacía Alcañz. Sin embargo, pronto encontraremos un camino (por la izquierda de la carretera) que conduce hacia el la parte septentrional del complejo lacustre. Al llegar a la Salada Grande hartemos una nueva parada, a $4 \mathrm{Km}$ de la anterior.

Este recorrido lo habremos efectuado íntegramente entre afloramientos de los materiales cenozoicos de la Depresión Geológica del Ebro, por donde efectuaremos el resto del recorrido.

En este lugar hay un importante conjunto de lagunas endorreicas, de aguas salobres. En estas, al evaporarse el agua se forman a menudo deposiciones de sal (de HALIA, fundamentalmente; aunque también hay EPSOMITA). De entre estas lagunas, la más importante es la de la Salada Grande, en donde estamos ahora situados. (fotografia 6).

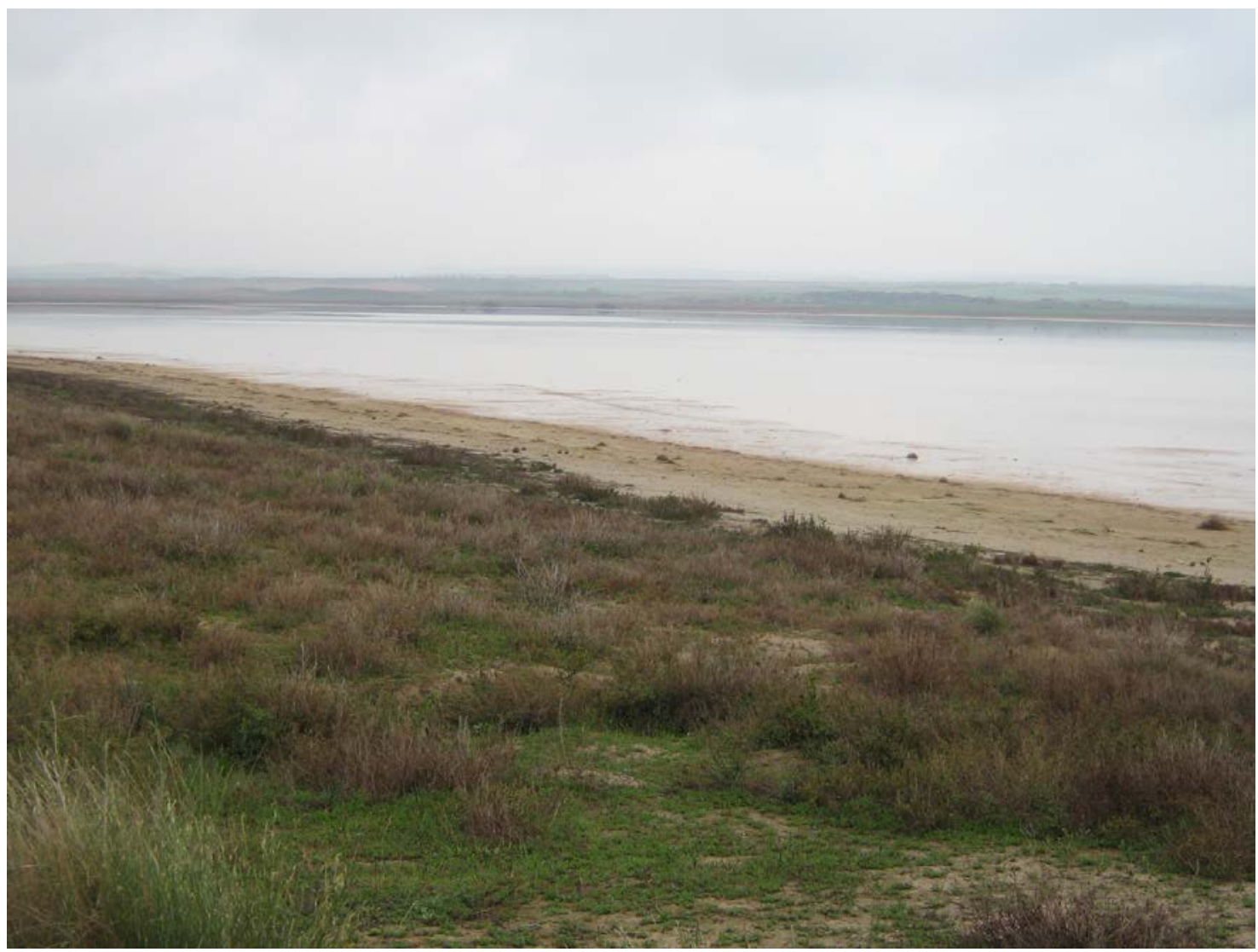

Fotografía 6. La Salada Grande, Alcañíz 
PARADA 7. TEJAR DE ALCAÑíz, (término municipal de Alcañíz, comarca del Bajo Aragón). (Hoja 469).

Tras realizar la parada anterior, cabe ahora hacer un breve recorrido con la finalidad de llegar hasta la población de Alcañíz. Ahí, poco después de la entrada, pasaremos por las cercanías de un antiguo tejar. En este lugar efectuaremos una nueva parada, tras recorrer unos $3 \mathrm{Km}$ desde la parada anterior.

En este recorrido habremos estado circulando por entre los afloramientos de los materiales cenozoicos de la Depresión Geológica del Ebro, en donde estamos ahora situados. Estos materiales apenas se hacen visibles, ya que a menudo se hallan recubiertos por los terrenos cuaternarios, generalmente detríticos. Precisamente, por encima de donde ahora estamos, hubo una antigua explotación de los materiales detríticos, para ser utilizados como áridos para la construcción.

En este lugar, había una antigua tejera. En ella reutilizaban los materiales arcillosos extraídos en las cercanías. Esta tejera, a pesar de su estado de abandono y deterioro gorma parte de nuestro patrimonio minero. (Fotografía 7).

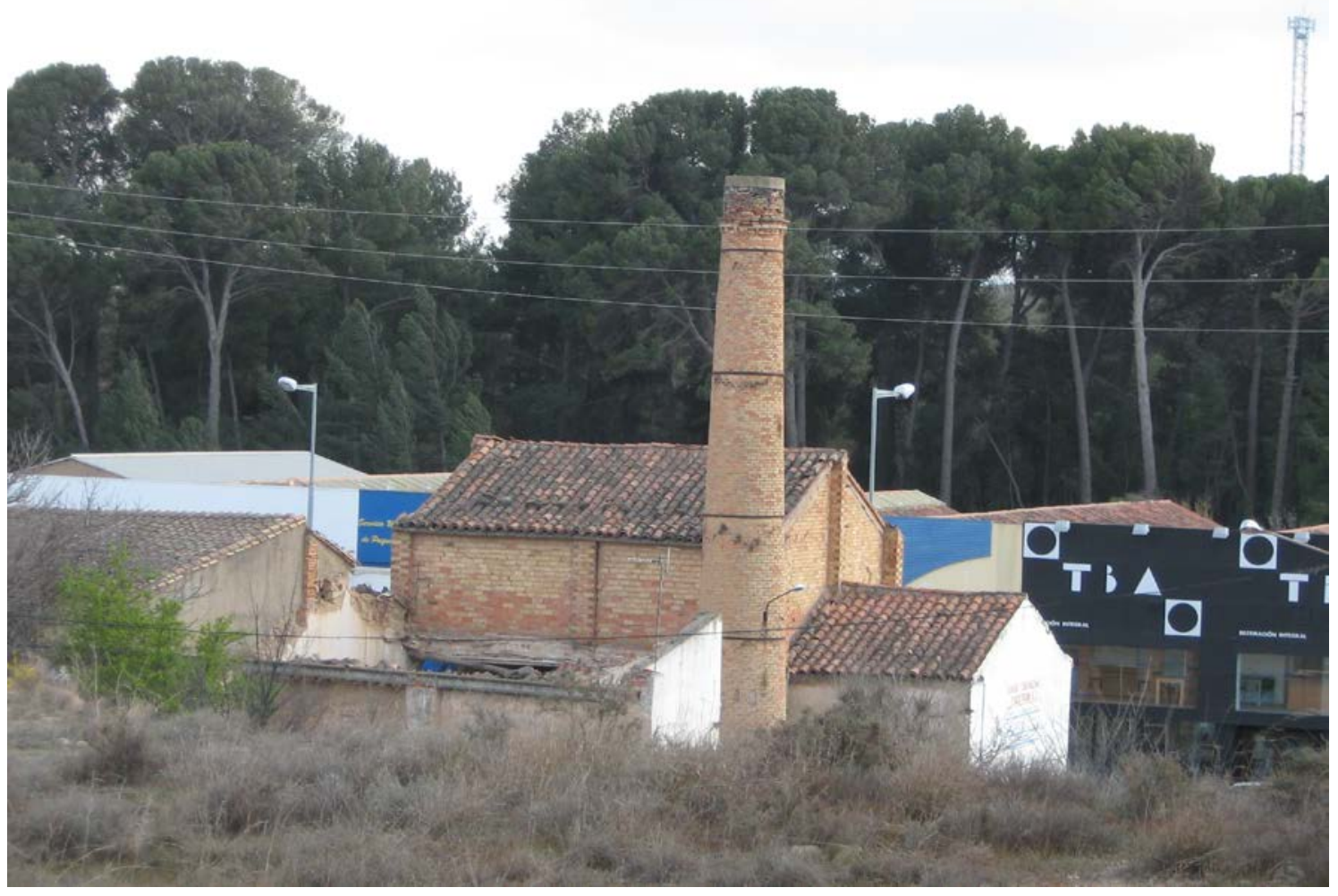

Fotografía 7. Un aspecto de la tejera de Alcañíz 
PARADA 8. EXPLOTACIÓN DE CALCARENITAS, (término municipal del Alcañíz, comarca del Bajo Aragón). (Hoja 469).

Después de efectuar la parada anterior, cabe atravesar totalmente la población de Alcañíz, con la finalidad de salir por la parte opuesta. Esta salida la efectuaremos por el antiguo trazado de la vía del ferrocarril. Por este camino, llegaremos pronto al que conduce hacía las actuales explotaciones de roca ornamental. Ahí, a unos $3 \mathrm{Km}$ de la parada anterior, efectuaremos la presente.

En este recorrido hemos ido encontrando afloramientos de los materiales cenozoicos de la Depresión Geológica del Ebro. A menudo, estos materiales se hallan recubiertos por terrenos cuaternarios detríticos. Estos, a veces han sido explotados para la obtención de áridos; así, en este recorrido habremos encontrado dos antiguas explotaciones de estos materiales.

Por otra parte, al llegar al lugar de la parada, habremos encontrado unos afloramientos de los niveles de calcoarenitas que forman parte de la Depresión Geológica del Ebro. Estos materiales han sido explotados en diversos lugares, con la finalidad de ser utilizados como roca ornamental. Así, en este lugar hay una importante explotación, actualmente en activo, para el beneficio de estas rocas. (fotografía 8 ).

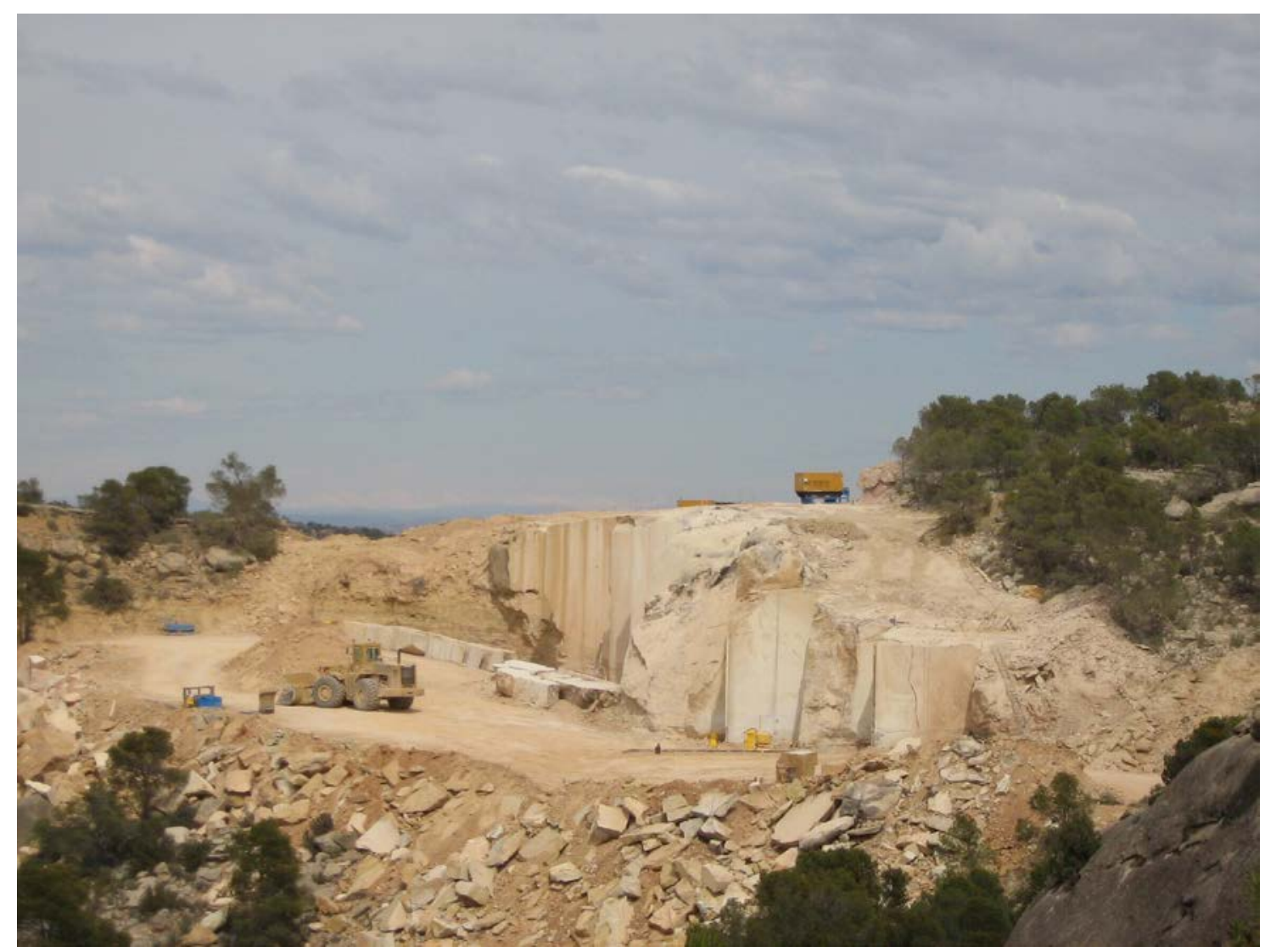

Fotografía 8. Aspecto de la explotación actual 
PARADA 9. CARRETERA AL EMBALSE DE CASPE, (término municipal de Alcañíz, comarca del Bajo Aragón). (Hoja 469).

Tras realizar la parada anterior, cabe casi retornar hasta el pueblo de Alcañíz. Antes de llegar a él, encontraremos la carretera nacional $\mathrm{N}-211$, por la cual habremos de continuar brevemente hacía el Norte. Al encontrar la carretera que conduce al Embalse de Caspe, habremos de tomarla. Apenas a $1 \mathrm{~km}$ del inicio de este camino ( $\mathrm{y}$ a unos $4 \mathrm{~km}$ de la parada anterior), efectuaremos una nueva parada.

En este recorrido, habremos ido encontrando afloramientos de los materiales cenozoicos de la Depresión Geológica del Ebro, en donde continuamos estando situados. A menudo, estos materiales se hallan recubiertos por terrenos detríticos cuaternarios.

En este lugar, y mirando hacia el norte, pueden verse unos interesantes ejemplos de paleocanales. Estos canales, al igual que los de Caspe, constituyen un buen ejemplo de nuestro patrimonio minero.

\section{EN ESTE LUGAR FINALIZA EL RECORRIDO DEL PRESENTE ITINERARIO}

\section{BIBLIOGRAFIA}

GUIMERÀ, J. et altri (1992).- Geologia (II), Història Natural dels Països Catalans, Vol. 2, 547 pag. Enciclopèdia Catalana, S.A. Barcelona.

MATA-PERELLÓ, J.M. (1992).-.Inventario Mineralógico de la comarca de la Tierra Baja Guadalope (Aragón). Rodeno, 28, 20 pag. Manresa.

MATA-PERELLÓ, J.M. (1995).- Itinerari geològico - mineralògic per les comarques de la terra de Montalbán, la Tierra Baja-Martín i la Tierra Baja-Guadalope: d'Andorra a Aliaga, a la Zoma i a Alcañiz. Inédito. 6 pag. Manresa.

MATA-PERELLÓ, J.M. (1996a).- Itinerari geològico - mineralògic per les comarques del Matarranya i de laTierra Baja-Guadalope: des de Calaceite a Valderrobres i Alcañiz. Inédito. 14 paginas. Manresa.

MATA-PERELLÓ, J.M. (1996b).- itinerari geològico - mineralògic per les comarques aragoneses de la Tierra de Montalbán, de la Tierra Baja-Martín i de la Tierra BajaGuadalope: des d’Alcañís a Andorra, Aliaga i a la Zoma. Inédito. 20 paginas. Manresa.

MATA-PERELLÓ, J.M. (1999).- Apunts per a un itinerari geològico - mineralògic per les comarques aragoneses de la Tierra Baja-Guadalope, la Ribera Baja del Ebro i els Monegros: des d’Alcañíz a Sástago i a Bujaraloz. Inédito. 6 pag. Manresa.

MATA-PERELLÓ, J.M. (2003a).- Itinerari geològic i mineralògic des d’Alcañiz a Morella passant per Foz Calanda, Aguaviva, Sorita, la Balma i Forcall. Inedito. 13 paginas. Manresa. 
MATA-PERELLÓ, J.M. (2003b).- Itinerari geològic i mineralògic per les comarques de la Tierra Baja-Guadalope, Tierra Baja-Martín i Tierra de Montalbán: des d'Alcañiz a Crevillent i a Gargallo. Inédito. 9 pag. Manresa.

MATA-PERELLÓ, J.M. (2003c).- Itinerari geològic i mineralògic per les comarques de la Ttierra Baja-Guadalope, Tierra Baja-Martín i Tierra de Montalbán: des d'Alcañiz a Crevillent, la Zoma i a Utrillas. Inédito. 14 pag. Manresa.

MATA-PERELLÓ, J.M. i SANZ BALAGUÉ, J. (1993).- Guía de identificación de Minerales, adaptada fundamentalmente a la Península Ibérica. Parcir, Edic. Selectas, 243 páginas. Manresa.

RIBA ARDERIU, O. et altri (1976).- Geografia Física dels Països Catalans. Edit Ketres. 211 pàgines. Barcelona. 